\title{
A Gestão Ambiental no Poder Judiciário: Estudo Exploratório de um Tribunal de Justiça ${ }^{1}$
}

\author{
The Environmental Management in the Judiciary: Exploratory Study a \\ Justice Court
}

\section{Gestión Ambiental en los Tribunales: Un Estudio Exploratorio en un Tribunal de Justicia}

\author{
Leonel Gois Lima Oliveira \\ Doutorando em Administração \\ Escola Brasileira de Administração Pública e de Empresas \\ (EBAPE) - Fundação Getúlio Vargas \\ Av. General Afonso Albuquerque, s/n, Cambeba \\ CEP: 60.830-120 - Fortaleza, CE - Brasil \\ Telefone: (85) 3207-7064, e-mail: leonelgois@gmail.com

\section{Diana Santos Pontes} \\ Mestra em Administração - Universidade Estadual do Ceará \\ Técnica Judiciário do Tribunal de Justiça do Estado do Ceará \\ Av. General Afonso de Albuquerque Lima, s/no \\ Cambeba, CEP: 60830-120 - Fortaleza, CE - Brasil \\ Telefone: (85) 32077064, e-mail: dianasantos.ufc@gmail.com
}

\author{
José Marcelo Maia Nogueira \\ Mestre em Administração Pública e Governo pela FGV/SP \\ (EAESP) - Tribunal de Justiça do Estado do Ceará \\ Av. General Afonso de Albuquerque Lima, s/no \\ Cambeba, CEP: 60830-120 - Fortaleza, CE - Brasil \\ Telefone: (85) 32077064, Ramal: 7064 \\ e-mail: marcelomaia30@gmail.com \\ José Carlos Lázaro da Silva Filho, Dr. \\ Professor Adjunto da Universidade Federal do Ceará \\ Doutor em Planejamento Ambiental \\ Rua Marechal Deodoro , 400 4o Andar (Dept ${ }^{\circ}$. Administração), \\ Benfica, CEP: 60.020-060 - Fortaleza, CE - Brasil, Telefone: (85) \\ 35521426, e-mail: lazaro.ufc@gmail.com
}

\section{RESUMO}

A atuação da gestão ambiental nos órgãos judiciais também é uma das preocupações do Conselho Nacional de Justiça (CNJ), conforme a Recomendação no . 11/2007. O presente estudo de caráter exploratório tem por objetivo analisar os projetos e ações relacionadas à gestão ambiental implantados ou a serem implantados pelo Tribunal de Justiça do Estado do Ceará (TJCE) que estão de acordo com a recomendação do CNJ. Discutem-se também os resultados alcançados no cumprimento da Meta no 6 do Judiciário brasileiro para o ano de 2010. Os meios de investigação utilizados para o levantamento de dados envolveram a pesquisa documental e entrevistas semiestruturadas. A análise foi de natureza qualitativa e interpretativa, baseada na avaliação do conteúdo das respostas das entrevistas realizadas. Verificou-se que anteriormente a elaboração da referida norma, alguns projetos com princípios ambientais já eram realizados no TJCE. Quanto às atividades desenvolvidas ou projetos posteriores o TJCE busca atender os itens recomendados, exceto a aquisição de bens e materiais de consumo que levem em consideração os princípios da sustentabilidade. O projeto de maior destaque consiste na digitalização dos processos judiciais e administrativos permitindo assim uma redução significativa na utilização de papel.

Palavras-Chave: Gestão Ambiental. Poder Judiciário. Tribunal de Justiça.

\footnotetext{
${ }^{1}$ Artigo recebido em 08.01.2014. Revisado pelos pares em 20.04.2014 (blind review). Ajustado e Aceito para publicação em 10.08.2014. Recomendado para publicação por Dr. José Ribamar Marques de Carvalho (Editor Científico). Publicado em 15.08.2014. Organização responsável UACC/CCJS/UFCG.
} 


\begin{abstract}
The performance of the ambient management in the agencies judicial also is one of the concerns of the Justice National Council (CNJ), as the Recommendation $n^{\circ}$. 11/2007. This exploratory study aims to analyze the projects and actions related to environmental management deployed or to be deployed by the Justice Court of the State of Ceará (TJCE) that are in agreement with the CNJ's recommendation. It also discusses the results achieved in the fulfillment of Goal number 6 of the Brazilian Judiciary for the year 2010. The used ways of inquiry for the data-collecting had involved the documentary research and halfstructuralized interviews. The analysis was of qualitative and interpretative nature, based in the evaluation of the content of the answers of the carried through interviews. It was verified that previously the elaboration of the related norm, some projects with ambient principles already were carried through in the TJCE. How much to the developed activities or posterior projects the TJCE searches to take care of the recommended item, except the acquisition of goods and materials of consumption that take in consideration the principles of the support. The project of bigger prominence consists of the digitalization of administrative the actions at law and thus allowing a significant reduction in the paper use.
\end{abstract}

Keywords: Environmental Management. Judiciary. Justice Court.

\title{
RESUMEN
}

El papel de la gestión ambiental en los tribunales es también una preocupación del Consejo Nacional de Justicia (CNJ), de acuerdo con la Recomendación no. 11/2007. Este estudio exploratorio tiene como objetivo analizar los proyectos y acciones relacionadas con la gestión ambiental, desplegadas o que se desplegarán por el Tribunal de Justicia del Estado de Ceará (TJCE) que están de acuerdo con la recomendación del CNJ. También se analizan los resultados alcanzados en el cumplimiento del Objetivo $n \stackrel{\text { o }}{ }$ del Poder Judicial de Brasil para el año 2010. Medios de investigación utilizado para la recolección de datos en cuestión de investigación documental y entrevistas semiestructuradas. El análisis fue cualitativo e interpretativo, basado en la evaluación de las respuestas de las entrevistas. Se encontró previamente que el desarrollo de esta norma, algunos proyectos con los principios ambientales que ya se hicieron antes en TJCE. En cuanto a las actividades emprendidas o los proyectos posteriores al TJCE busca cumplir con los elementos recomendados, excepto la compra de bienes y materiales que tengan en cuenta los principios de la sostenibilidad. El proyecto más destacado es la digitalización de los procesos judiciales y administrativos, permitiendo así una reducción significativa en el consumo de papel.

Palavras Clave: Gestión Ambiental. Poder Judicial. Tribunal de Justicia.

\section{INTRODUÇÃO}

Com uma interpretação mais ampla dos conceitos difundidos de gestão ambiental nas organizações, é possível ver paralelos a serem implantados na gestão pública, tendo em vista a característica organizacional de um Tribunal de Justiça. Princípios como a integração de todas as atividades sobre as diretrizes ambientais, o comprometimento da alta administração e a educação ambiental são claramente aplicáveis em uma organização como esta. Corroborando este pensamento, Resende (2008) e Pereira Filho (2009) apontam que as principais ferramentas de gestão ambiental e de responsabilidade social encontram plena aplicabilidade no Poder Judiciário brasileiro, embora pouco se tenha colocado em prática. 
A atuação da gestão ambiental nos órgãos judiciais também é uma das preocupações do Conselho, conforme pode ser visto na Recomendação no. 11/2007 (CNJ, 2007) e na Meta Nacional $~ 6$ para o ano de 2010 (CNJ, 2011). A primeira recomenda a adoção de políticas públicas voltadas para a conscientização dos servidores e jurisdicionados sobre a necessidade de efetiva proteção ao meio ambiente, além da criação de comissões ambientais para o planejamento, elaboração e acompanhamentos das medidas implementadas (CNJ, 2007). Enquanto a segunda visava, no ano de 2010, reduzir pelo menos $2 \%$ (dois por cento) o consumo per capita (magistrados, servidores, terceirizados e estagiários) com energia, telefone, papel, água e combustível tendo como base os valores de consumo do ano anterior (2009) (CNJ, 2011).

O presente estudo apresenta como objetivo analisar os projetos e ações relacionadas à gestão ambiental implantados ou a serem implantados a partir de 2011 pelo Tribunal de Justiça do Estado do Ceará que estão conformes com a Recomendação n. ${ }^{-}$11/2007 do CNJ e discutir os resultados alcançados para o cumprimento da Meta $n^{\mathbf{0}} 6$ do ano de 2010.

O artigo está esquematizado em mais quatro seções, além desta introdução. A segunda seção descreve os fundamentos teóricos dos temas aqui envolvidos. Em seguida, é especificado o caminho metodológico adotado para a obtenção dos dados. No quarto momento são expostos os resultados e as análises da pesquisa de campo realizada, com os dados comparativos. No último item são feitas as considerações e recomendações finais.

\section{REFERENCIAL TEÓRICO}

\subsection{GESTÃO DO SETOR PÚBLICO - PODER JUDICIÁRIO}

A adoção de ferramentas gerenciais modernas para o setor público é algo recente no contexto nacional. O principal marco legal para a implantação de iniciativas nesse sentido consiste no Decreto-Lei no. 5.378, de 23 de fevereiro de 2005 que institui o Programa Nacional de Gestão Pública e Desburocratização, mais conhecido como GESPÚBLICA (BRASIL, 2005).

O GESPÚBLICA trata-se de uma política formulada partindo da premissa de que a gestão de órgãos e entidades públicos pode e deve ser excelente, sendo comparada com padrões internacionais de qualidade em gestão, sem deixar de ser pública. A qualidade da gestão pública tem que ser orientada para o cidadão, e desenvolver-se dentro do espaço constitucional demarcado pelos princípios da Administração Pública: legalidade, impessoalidade, moralidade, publicidade e eficiência (BRASIL, 1988; 2005). 
Ao longo da história o tema de gestão pública encontra maior ressonância quando abordado sobre o Poder Executivo ou Legislativo, principalmente o primeiro. Muito pouco era abordado ou lembrado quando relacionado ao Poder Judiciário, verificando-se um desequilíbrio entre os Três Poderes na quantidade de estudos no campo da Administração Pública. Esta área do conhecimento não acumula quantidades significativas de trabalhos que enfatizem o Poder Judiciário e sua gestão. Aragão (1997) e Arantes (2007) confirmam esta percepção ao alertarem sobre a exiguidade de estudos e pesquisas sobre o Poder Judiciário na área de Administração Pública no Brasil. Como forma de melhor verificar essa hipótese, o trabalho desenvolvido por Nogueira (2011) demonstra que cerca de $1 \%$ dos trabalhos acadêmicos retratam o tema "gestão do Poder Judiciário" nos anais dos principais Encontros de Pós-Graduação e Pesquisa em Administração do país e nos periódicos relacionados à Administração Pública no período de 1995 a 2008. Fato que se contrapõem ao interesse de estudo na área demonstrados pelos organizadores dos referidos eventos ou periódico. A escassez de estudos continua também realçada quando se buscam estudos empíricos na área do Direito e que envolvam aspectos de Gestão do Judiciário conforme apontado por Sadek e Oliveira (2012).

Nogueira (2011) apresenta a criação do CNJ como um contraponto ao baixo número de estudos acadêmicos. O CNJ passou a centralizar e divulgar dados estatísticos dos tribunais brasileiros por meio de seus relatórios. Tal prática possibilitou o acesso a informações, abrindo caminho para a realização de mais estudos (SADEK; OLIVEIRA, 2012). Dado que é possível visualizar em outros estudos que abordam o Poder Judiciário e os aspectos que envolvam sua Gestão, principalmente quando o assunto é a questão do aumento da eficiência técnica (gestão dos processos judiciais) (YEUNG; AZEVEDO, 2011; NOGUEIRA et al., 2012; GOMES; GUIMARÃES, 2013). Fato que demonstra um aumento na eficiência bem como novas perspectivas sobre a Gestão do Poder Judiciário de maneira mais generalizada, envolvendo aspectos econômico, ambientais e sociais. $\mathrm{O}$ CNJ surge com a tarefa principal de controlar, em âmbito nacional, as atividades administrativas e financeiras de todos os tribunais brasileiros, inclusive os tribunais superiores. Utiliza-se de encontros, resoluções, recomendações, metas a serem alcançadas e outras formas de comunicação para uma padronização das formas de atuação (VIEIRA; PINHEIRO, 2008).

Segundo a Agência CNJ de Notícias (2009), o CNJ tem promovido à disseminação de ideologias que incentivam a execução de Planejamentos Estratégicos nas diversas instâncias do Poder Judiciário brasileiro, visando, dentre outros aspectos, a promoção de maior transparência e modernização da gestão do Judiciário. Tais temas estão diretamente ligados à agenda da gestão pública contemporânea. 


\subsection{GESTÃO AMBIENTAL}

Dentro do novo paradigma econômico ambiental, no qual a sociedade começa incluir os valores ligados ao meio ambiente nos aspectos socioeconômicos da sua qualidade de vida, o poder público tem um importante papel. Atualmente no Brasil, a Administração Pública também pode ser dividida em três esferas básicas: federal, estadual e municipal. Estas atuam de maneiras distintas, obtendo resultados diversos, conforme a importância que a comunidade percebe a questão ambiental em sua vida.

Quanto às maneiras normais de atuação do poder público na gestão ambiental, Barbieri (1997) monta um quadro (Quadro 1) no qual divide os instrumentos políticos em três gêneros: Comando e Controle; Econômico; e Diversos.

Quadro 1: Principais instrumentos de política ambiental pública.

\begin{tabular}{|l|l|}
\hline Gênero & Espécie \\
\hline \multirow{4}{*}{$\begin{array}{l}\text { Comando e } \\
\text { Controle }\end{array}$} & Padrão de emissão \\
\cline { 2 - 2 } & Padrão de desempenho \\
\cline { 2 - 3 } & Proibições e restrições sobre produção, comercialização e uso de produtos \\
\cline { 2 - 3 } & Licenciamento Ambiental \\
\hline \multirow{5}{*}{ Econômico } & Tributação sobre poluição \\
\cline { 2 - 2 } & Tributação sobre o uso de recursos naturais \\
\cline { 2 - 3 } & Incentivos fiscais \\
\cline { 2 - 3 } & Criação e sustentação de mercados \\
\cline { 2 - 2 } & Financiamentos em condições especiais \\
\cline { 2 - 3 } & Licenças negociáveis \\
\hline \multirow{5}{*}{ Diversos } & Educação ambiental \\
\cline { 2 - 3 } & Reservas ecológicas e outras áreas de proteção ambiental \\
\cline { 2 - 3 } & Informações aos públicos \\
\cline { 2 - 2 } & Mecanismos administrativos e jurídicos de defesa do meio ambiente \\
\hline
\end{tabular}

Fonte: Barbieri (1997, p. 143).

Os instrumentos de comando e controle são os mais facilmente associados à Administração Pública, que muitas vezes se limita a este. Padrões de emissões e desempenho, restrições e proibições são os principais instrumentos destes tipos e geralmente se encontram em leis estaduais, com órgãos fiscalizadores (controle) vinculados ao Estado.

Os instrumentos econômicos vão um pouco mais além, são aplicados visando incentivar a mudança de comportamento das pessoas e das organizações, ligando a interferência das mesmas no meio ambiente com benefícios e custos. E devido a focos 
diferentes dos instrumentos em si, podemos identificar genericamente: as tributações sobre a poluição (emissão), sobre o uso dos recursos naturais, incentivos fiscais, financiamentos em condições especiais, criação e sustentação de mercados, variando em detalhes conforme a abordagem.

Algumas organizações não governamentais com foco empresarial têm desenvolvido princípios para a gestão ambiental, visando criar um direcionamento das organizações para uma postura mais ambientalmente responsável. Citam-se os seguintes exemplos: os princípios da Coalition for Environmentally Responsible Economics (CERES), de 1990; os estabelecidos pela Câmara de Comércio Internacional (CCI); uma versão nacional do "Responsible Care" criado no Canadá nos meados dos anos 80 promovida pela Associação Brasileira da Indústria Química (ABIQUIM). Estes princípios estão, de certa forma, contidos e passíveis de avaliação na norma de caráter ambiental desenvolvida pela organização internacional de Normas ISO, a série ISO 14000, ou ainda podem colocados em parâmetros de qualidade, conforme o Total Quality Environmental Management (TQEM) (NASCIMENTO; LEMOS; MELLO, 2008).

Usualmente o papel do Estado é visto através dos instrumentos e neste ponto devemos entrar mais a fundo nos conceitos da gestão ambiental pública, pois atualmente já há conceitos e modelos bem desenvolvidos de Sistemas de Gestão Ambiental (SGA) para organizações, com um foco em empresas, porém alguns dos princípios dos mesmos podem ser focados em um Tribunal de Justiça, por exemplo.

Segundo o CNJ (2009), os Tribunais de Justiça cumprem o seu papel público ao promover ações com foco ambiental, quando, por exemplo, fazem a administração do lixo, realizando a deposição correta do mesmo, com uma visão proativa ambientalmente; incentivado a reciclagem; instituindo a separação seletiva do mesmo; e promovendo a conscientização de todos os seus funcionários da necessidade de se engajar na causa ambiental. Neste entendimento, destaca-se a instituição de uma meta prioritária nacional para o ano de 2010 que buscava a redução, a pelo menos $2 \%$, o consumo per capita de água, energia, telefone, papel e combustível. A referência de comparação consistia nas médias de valores de consumo no ano de 2009 (CNJ, 2011). O resultado geral da meta pode ser observado no Quadro 2. 
Quadro 2. Panorama nacional para o cumprimento da Meta 6 de 2010.

\begin{tabular}{|c|c|c|c|c|c|c|}
\hline Parâmetros & $\begin{array}{l}\text { Energia } \\
\text { elétrica } \\
\text { (Kwh) }\end{array}$ & $\begin{array}{l}\text { Telefone } \\
(\mathrm{R} \$)\end{array}$ & $\begin{array}{l}\text { Água } \\
\left(\mathrm{m}^{3}\right)\end{array}$ & $\begin{array}{l}\text { Papel ( } \mathrm{n}^{\underline{0}} \\
\text { de resmas) }\end{array}$ & $\begin{array}{l}\text { Combustível } \\
\text { (l) }\end{array}$ & $\begin{array}{l}\text { Economia } \\
\text { Total }\end{array}$ \\
\hline $\begin{array}{l}\text { Consumo per capita em } \\
31 / 12 / 2009\end{array}$ & $2.150,04$ & 294,49 & 16,76 & 9,18 & 96,93 & \\
\hline $\begin{array}{l}\text { Consumo per capita em } \\
31 / 12 / 2010\end{array}$ & $2.181,89$ & 237,46 & 17,54 & 9,31 & 190,71 & \\
\hline Percentual de Redução & $-1,44 \%$ & $19,36 \%$ & $-4,66 \%$ & $-1,47 \%$ & $-96,75 \%$ & $-16,99 \%$ \\
\hline Percentual de Cumprimento & $-72 \%$ & $968 \%$ & $-233 \%$ & $-73,5 \%$ & $-4837,5 \%$ & $-849,60 \%$ \\
\hline
\end{tabular}

Fonte: CNJ (2011, p. 162).

As medidas de cada um dos indicadores seriam consideradas para a verificação do cumprimento geral, sendo calculado a partir de uma média ponderada. Portanto, o tribunal poderia até não conseguir reduzir o percentual exigido em um dos itens, mas teria que gerar uma redução maior nos outros como efeito de compensação. Portanto, pode-se perceber no cenário nacional que a meta não foi cumprida. Dentre todos indicadores analisados, verificou-se apenas a diminuição no consumo do uso do telefone, não sendo suficiente para o cumprimento da meta. Porém, a redução do consumo de telefone apresenta mais um caráter de controle de gastos do que propriamente uma preocupação com os aspectos ambientais.

A meta foi estabelecida visando o cumprimento de todos os tribunais, porém nem todos conseguiram atender a todos os requisitos (61 de 91 tribunais no Brasil). Com um olhar mais detalhado percebe-se que alguns tribunais conseguiram o cumprimento a meta, sendo 20 (vinte) tribunais da Justiça Estadual, 2 (dois) tribunais da Justiça Militar, 14 (catorze) tribunais da Justiça Eleitoral, 19 (dezenove) tribunais da Justiça do Trabalho, 4 (quatro) tribunais da Justiça Federal e 2 (dois) tribunais superiores (CNJ, 2011).

\subsection{A RECOMENDAÇÃO N. 11/2007 E O CNJ AMBIENTAL}

O mapa estratégico do Poder Judiciário demonstra que questões relacionadas à Responsabilidade Social e Ambiental devem ser tratadas por todos os Tribunais do país (OLIVEIRA, PONTES, SOARES, 2011). Para tanto, estabeleceu a criação do CNJ Ambiental como órgão auxiliador para a realização de ações do Poder Judiciário para a proteção do Meio Ambiente, através do monitoramento das ações realizadas pelos Tribunais, bem como, pelo acompanhamento do julgamento de causas ambientais (CNJ AMBIENTAL, 2009). 
A Recomendação n. ${ }^{\circ}$ 11/2007 apresenta políticas públicas que podem ser adotadas pelos Tribunais do país buscando um acompanhamento das medidas que visam à correta preservação e recuperação do meio ambiente. Os seguintes exemplos são apontados pela referida norma (CNJ, 2007, p. 1):

a) utilização de papel reciclado e não clorado nos impressos do Poder Judiciário, sejam de natureza administrativa ou processual;

b) instituição da coleta seletiva de resíduos, destinando recipientes individuais para plástico, papel, metal e vidro, e a ulterior doação do material coletado a entidades assistenciais que se responsabilizem pela correta utilização do material para a devida reciclagem;

c) aquisição de impressoras que imprimam, automaticamente, em frente e verso;

d) aquisição de bens e materiais de consumo que levem em consideração o tripé básico da sustentabilidade: ambientalmente correto, socialmente justo e economicamente viável;

e) utilização sustentável da energia e dos combustíveis; e

f) utilização de edifícios com observância da proteção ao meio ambiente.

A norma está em vigor e serve de base para a Linha de Ação do CNJ Ambiental. Esta consiste em visitas aos Tribunais para propagar a importância do diagnóstico ambiental, analisando as problemáticas encontradas pelos tribunais na implantação de ações voltadas para a adesão aos termos propostos na Recomendação n.. 11/2007. Além disso, promove a realização de eventos, palestras, fóruns, seminários e congressos relacionados ao tema. (CNJ AMBIENTAL, 2009; CNJ, 2010).

Até o final de 2009, o CNJ Ambiental havia realizado visitas a 442 comarcas em todo o país, sendo 420 em comarcas do interior dos Estados (CNJ AMBIENTAL, 2009); As regiões Sudeste e Centro-Oeste foram as que tiveram mais comarcas monitoras, respectivamente, 131 e 130 comarcas que desenvolvem ao menos um dos pontos da Recomendação n. ${ }^{-}$11/2007. Na região Nordeste, o estado do Ceará destaca-se com mais de 20 comarcas no desenvolvimento de atividades socioambientais no âmbito do Poder Judiciário (CNJ, 2010).

\section{PROCEDIMENTOS METODOLÓGICOS}

O propósito do artigo, de compreender as questões relacionadas à gestão ambiental no Poder Judiciário, conduziu à escolha da abordagem qualitativa para realizar a investigação, opção justificada pela assertiva de Richardson $(1999$, p. 80) de que essa pesquisa é "uma forma adequada para entender a natureza de um fenômeno social". O autor sugere, também, o uso das observações qualitativas, "como indicadores 
de funcionamento de estruturas sociais".

Como estratégia de pesquisa, optou-se pelo desenvolvimento de um estudo de caso, que, segundo Yin (2010), é preferido quando o controle que o investigador tem sobre os eventos é muito reduzido, ou ainda quando o foco temporal está em fenômenos contemporâneos, dentro do contexto de vida real. Godoy (1995, p. 25-26) expõe ainda que, "adotando enfoque exploratório e descritivo, o pesquisador que pretende desenvolver um estudo de caso deverá estar aberto às suas descobertas".

Os meios de investigação utilizados para o levantamento de dados envolveram a pesquisa documental e entrevistas semiestruturadas. A pesquisa documental foi feita com base em material obtido junto ao CNJ Ambiental, aos Tribunais de Justiça dos Estados de Sergipe (TJSE), Distrito Federal e dos Territórios (TJDFT), Santa Catarina (TJSC) e, principalmente, do Ceará (TJCE), incluindo relatórios e material institucional, além de informações disponibilizadas nos portais institucionais na Internet. Foram objetos de consulta e análise as seguintes fontes de dados: material de divulgação; os portais eletrônicos dos Tribunais de Justiças estaduais citados; estatuto; regimento interno, resoluções, e demais normas. Utilizou-se o Estado do Ceará para a realização do estudo de caso devido ao destaque alcançado no monitoramento do CNJ Ambiental para a região Nordeste, o bom resultado no cumprimento da meta 6 de 2010, bem como, pela maior facilidade de acesso dos autores junto aos principais gestores do TJCE.

Posteriormente, realizaram-se entrevistas semiestruturadas individuais, com base em um roteiro pré-definido, desenvolvido de forma flexível e adaptado conforme as particularidades percebidas durante o transcorrer de cada entrevista. $O$ roteiro continha questões que permitiam extrair dos entrevistados informações sobre suas experiências com a gestão ambiental, os esforços para o cumprimento da Meta 6 de 2010, principalmente comparando com os itens da Recomendação n. ${ }^{\circ}$ 11/2007 do CNJ e com as documentações de experiências divulgadas pelos outros Tribunais. Os entrevistados foram comunicados sobre o propósito da investigação empírica e a importância de sua colaboração para o estudo, bem como sobre a garantia de confidencialidade. Por questões de sigilo não estão mencionados os nomes e os cargos dos entrevistados. Estes são servidores que estão lotados nas Secretarias e Assessorias do TJCE e foram escolhidos por atuarem em projetos que estão relacionados com os aspectos de ambientais, bem como pelos critérios de disponibilidade e conveniência. No total foram 20 (vinte) entrevistas, sendo que 15 (quinze) já estavam previamente agendadas com base nos critérios mencionados anteriormente. Adotou-se, também, a técnica de bola de neve (snowballing), permitindo que entrevistados tivessem a oportunidade de indicar outros nomes para uma melhor explicação sobre o andamento de alguns projetos. As entrevistas foram realizadas ao longo do segundo semestre de 2010 e do primeiro 
semestre de 2011.

A análise foi de natureza qualitativa e interpretativa, baseada na avaliação do conteúdo das respostas das entrevistas realizadas, e na confrontação dos resultados com os itens do referencial teórico utilizado (não foram utilizados métodos estatísticos). Buscou-se identificar elementos históricos, bem com o detalhamento de projetos que estão diretamente relacionados aos itens da Recomendação n. ำ 11/2007 do CNJ e confrontando com os dados do levantamento promovido pelo CNJ Ambiental (CNJ AMBIENTAL, 2009).

\section{APRESENTAÇÃO E DISCUSSÃo DOS RESULTADOS}

O material coletado é analisado tendo como marco divisor a Recomendação n. ${ }^{\circ}$ 11/2007 do CNJ. Inicialmente, apresenta-se uma breve caracterização do Tribunal de Justiça do Estado do Ceará e em seguida, as atividades desenvolvidas pelo órgão antes e depois da Recomendação. Finaliza-se com a apresentação dos resultados alcançados pelo TJCE para o cumprimento da Meta 6 do ano de 2010.

\subsection{Caracterização do Tribunal de Justiça do Estado do Ceará}

O Tribunal de Justiça do Estado do Ceará é o órgão do Poder Judiciário com jurisdição em todo o Estado, para decidir, em segunda instância, todas as questões relativas à Justiça. Vale ressaltar, que, em primeira instância, as decisões proferidas se dão no âmbito das Comarcas da Capital e do interior, as quais agregam os Juizados Especiais e as Varas (TJCE, 2011a).

Instalado solenemente em 1874 com a denominação “Tribunal da Relação da Província do Ceará", este órgão, que tem, ao longo de sua história, contribuído no processo de construção da cidadania do povo cearense, dignificando as ações judiciárias em sua historicidade, recebeu a denominação de Tribunal de Justiça somente com a Constituição Estadual de 23 de junho de 1947 (TJCE, 2011a).

O TJCE exerce sua atividade-fim através de seus órgãos julgadores (Tribunal Pleno; Câmaras Cíveis e Criminais Reunidas; Primeira, Segunda, Terceira e Quarta Câmaras Cíveis Isoladas; Primeira e Segunda Câmaras Criminais Isoladas; e Conselho da Magistratura) e da Secretaria Judiciária (TJCE, 2011a).

Por sua vez, dão sustentação à atividade-fim as Assessorias e as Secretarias. São esses setores administrativos, juntamente com a Presidência e Vice-Presidência do TJCE, os responsáveis por estabelecer as diretrizes de atuação do órgão. Destaca-se, que, a cada dois anos, é definida uma nova Administração para o Tribunal, o que permite que 
haja o aprimoramento e o estabelecimento de novas políticas, ocorrendo, dessa forma, uma constante renovação na instituição.

\subsection{Atividades desenvolvidas anteriormente a Recomendação n. ${ }^{0}$ 11/2007}

A preocupação com os recursos naturais ou com questões relacionadas à gestão ambiental já foram objetos de atenção das gestões do Tribunal de Justiça mesmo antes da edição da Recomendação n.. $11 / 2007$ do CNJ. Através da pesquisa documental em relatórios de gestões anteriores e regulamentações internas foi possível encontrar dados que demonstrasse essa preocupação. Embora possa ser entendida como aspectos pontuais, já sinalizam esforços de gestões anteriores para a uma maior conscientização da diminuição do uso de recursos naturais, conforme será explicado a seguir.

A principal ação realizada consiste na diminuição do consumo de papel nas atividades de trabalho. A diminuição da quantidade de exemplares do Diário da Justiça impressos permitiu a redução de 12.500 (doze mil e quinhentas) folhas de papel por dia, proporcionando também uma diminuição no uso de toner, de energia e mão de obra, gerando conjuntamente uma economia mensal de R\$ 59 mil. Esta diminuição foi ocasionada pelo acesso gratuito do Diário da Justiça eletrônico através do portal do Poder Judiciário cearense na Internet a partir de março de 2007 (TJCE, 2009a).

A racionalização de insumos como papel e energia também foi objeto de regulamento pela portaria n. ${ }^{\circ} 863 / 2006$, de 13 de novembro de 2006. Esta normatizou a utilização de frente e verso do papel para a impressão e cópia reprográficas realizadas que se estendam a mais de uma página. O Departamento de Informática ficou encarregado de elaborar um tutorial com os procedimentos a serem adotados pelos servidores para utilização das impressoras e máquinas reprográficas. Outro ponto consistia na redução pela metade da iluminação elétrica dos corredores tanto internos, destinados exclusivamente aos servidores, como dos corredores externos, destinados ao público em geral (DFCB, 2006).

Verificou-se que as impressoras utilizadas pelo Tribunal de Justiça que possuem a opção de impressão no anverso e verso são todas alugadas. Há um quantitativo de 256 impressoras que são utilizadas pelos servidores do órgão, mas não fazem parte do patrimônio organizacional, conforme apontado pela Diretoria de Patrimônio e confirmado com uma Diretora da Secretaria de Tecnologia da Informação. Constatou-se a existência de um projeto para aquisição de impressoras com essa função que será detalhado na seção posterior.

$\mathrm{O}$ acesso ao acompanhamento das fases processuais pela Internet e o recebimento das atualizações dos processos por correio eletrônico através do Sistema Push (SPUSH) 
permitem uma diminuição da ida de jurisdicionados pessoalmente às unidades judiciárias. O SPUSH é um serviço gratuito que tem como objetivo facilitar o acompanhamento dos processos selecionados pelos interessados através do envio de emails informando o andamento processual, embora não dispensando o uso dos instrumentos oficiais de comunicação para formalização e produção de efeitos legais (TJCE, 2011a). Desta forma, o TJCE passa a colaborar com a redução na emissão de poluentes oriundos de combustíveis fósseis e promovem a redução da impressão de papeis contendo informações sobre os processos em tramitação. Assemelha-se a prática destacada pelo TJDFT (2010) na sua agenda socioambiental. Vale ressaltar que durante a implantação do SPUSH no TJCE, ainda não havia um documento formal que indicasse o compromisso do tribunal com uma agenda relacionada às causas socioambientais.

A partir das entrevistas realizadas, algumas ações de gestão ambiental foram apontadas como anteriores a Recomendação n. ${ }^{-11 / 2007}$. Por exemplo, a prática de coleta seletiva de resíduos sólidos já chegou a ser implantada no TJCE formalmente em uma das gestões do órgão. Segundo os entrevistados, o trabalho desenvolvido a cerca de 10 anos atrás não gerou grandes resultados devido o baixo investimento na formação continuada em Educação Ambiental. Portanto, há uma percepção de que os instrumentos de política ambiental pública caracterizada como "diversos" por Barbieri (1997) deveriam ter sido adotados pelos antigos dirigentes do TJCE. Havia espaço para o fomento da Educação Ambiental, de informações adequadas para o público alvo do Tribunal, bem como uma maior sistematização de mecanismos administrativos para a defesa do meio ambiente. $O$ passado não pode ser revisto, mas pode deixar marcas ao longo do tempo. Neste caso, por exemplo, o costume de separar os resíduos sólidos gerados foi se perdendo ao longo do tempo, restando apenas as lixeiras com a divisão dos materiais que duram até os dias atuais.

\subsection{Atividades desenvolvidas ou projetos posteriores a Recomendação n.o 11/2007}

A principal atividade desenvolvida posteriormente a Recomendação n.. 11/2007 consiste nos procedimentos de digitalização dos processos judiciais. O projeto está em fase de implantação desde 2008 e já consegue obter resultados significativos na economia de uso de papel. Os novos processos judiciais dos Juizados Especiais Cíveis e Criminais da justiça cearense já estão todos no formato digital. Vale ressaltar que o TJCE foi o primeiro Tribunal do país a enviar todos os recursos interpostos digitalizados ao Superior Tribunal de Justiça (STJ). Havia uma previsão de que todos os processos judiciais estivessem virtualizados até o início de 2011 (TJCE, 2011a), mas que não foi possível. Destaca-se apenas que os processos administrativos já estão todos no formato 
digital. Após a digitalização, todos os papeis são triturados por organizações sem fins lucrativos conveniadas previamente e foram reciclados, conforme apontado pela Diretora da Secretaria de Tecnologia da Informação e pelo Assessor da Presidência. Em outubro de 2011, foi publicado um edital que permitiu o cadastro das entidades. O papel deveria ser transportado pela instituição, sendo necessária a presença de um servidor do TJCE durante o processo de trituração (TJCE, 2011b)

Buscando atender as políticas públicas recomendadas pelo CNJ, o TJCE pretendia adquirir novas impressoras e máquinas reprográficas que tenham automaticamente a opção de impressão ou reprografia em frente e verso. O projeto de aquisição consta que serão compradas 615 impressoras multifuncionais, 1229 impressoras comuns, cinco impressoras coloridas e 10 copiadoras de grande porte, segundo projeto apresentado pela Diretora da Secretaria de Tecnologia da Informação e Chefe do Setor de Licitações e Contratos. Esta opção pelo uso de frente e verso do papel consistirá numa atividade complementar da Portaria 863, de 13 de novembro de 2006, anteriormente citada, fazendo com que se torne desnecessário a tutoria do Departamento de Informática. Vale ressaltar que o nível de impressão pretender ser cada vez mais reduzido, pois o projeto de digitalização pretende ser ampliado para outros setores, fazendo com o consumo de papel fique constantemente num nível baixo.

As obras e reformas dos ambientes do TJCE são planejadas visando à proteção do meio ambiente. Um exemplo fornecido durante as entrevistas foi a construção do novo Fórum da Comarca de Caucaia (município da Região Metropolitana de Fortaleza). O projeto contou com novos de aparelhos de ar condicionado que permite um menor consumo de energia e facilidade na limpeza e reaproveitamento da água utilizada para refrigeração, conforme destacado pela Diretora do Departamento de Engenharia.

O Planejamento Estratégico do TJCE foi finalizado em 2007 e já contou com um objetivo estratégico voltado a itens relacionados com a gestão ambiental, que consiste em "ampliar a sua responsabilidade socioambiental" (TJCE, 2011a). No início de 2009, o Planejamento Estratégico foi reformulado, mas o objetivo permaneceu, possuindo alguns projetos em fase inicial de implantação. A título de exemplificação, constam no Plano Estratégico 2010-2014: uma nova sistemática do abastecimento dos veículos e o retorno da instituição da coleta seletiva de resíduos com procedimentos posteriores de reciclagem outros que vão de encontro com a Recomendação n.. 11/2007 (OLIVEIRA; PONTES; SOARES, 2011).

O abastecimento dos veículos busca a uma maior utilização de combustíveis de origem não fóssil, principalmente álcool. Os carros adquiridos recentemente pelo TJCE possuem a tecnologia de bicombustíveis, os chamados carros flex. Está prevista uma 
substituição gradativa de toda a frota por veículos com a possibilidade de serem abastecidos a álcool.

A tentativa de retomar as atividades de coleta seletiva de resíduos buscava a concretização e a permanência da cultura de coleta e reciclagem dos resíduos sólidos produzidos. Vale ressaltar que não são considerados resíduos para este fim, os papeis resultante dos processos já digitalizados. Havia a intenção de venda dos resíduos coletados para uma instituição de reciclagem, gerando um valor financeiro que permitirá a realização de atividades direcionadas para a Educação Ambiental. Portanto, demonstra o esforço da gestão em promover a conscientização de todos os servidores e dos demais operadores do Direito que circulam pelos ambientes do TJCE. Planejava-se a realização de diferentes atividades como, por exemplo, palestras, seminários, cursos, anúncios no sistema interno de som, envio de cartilha para os correios eletrônicos dos servidores, dentre outras ferramentas de comunicação.

A comunicação interna através de mecanismos digitais vem sendo gradativamente colocada à disposição de todos os servidores, como o estabelecimento de mecanismos de mensagem instantânea corporativa. A renovação do sistema de correio eletrônico, também, permite uma maior funcionalidade como o agendamento de reuniões, acompanhamentos de trabalhos rotineiros a serem realizados e agenda de contatos, conforme enfatizado pelo Assessor de Planejamento que utiliza essas ferramentas em conjunto com outras para o gerenciamento dos projetos em todo o Estado. Isto demonstra que esse mecanismo de comunicação não se restringe somente ao uso de mensagens eletrônicas, gerando um maior dinamismo nas rotinas de trabalho, bem como outro mecanismo de redução do uso de papel.

A utilização de papel reciclado e não clorado nos impressos foi implantado pelo TJCE através da Portaria n. - 1390/2009, de 30 de outubro de 2009, conforme é recomendado pelo CNJ (TJCE, 2009b). O projeto de aquisição e substituição gradativa do tipo de papel já havida sido discutido pelos gestores do órgão, mas a principal objeção consiste no impacto financeiro da adoção de tais medidas. O período atual de transição é demonstrado no teor de seu artigo 1으, onde determinar que "nos impressos do Poder Judiciário do Estado do Ceará, tanto de natureza administrativa como processual, sempre que possível, sejam utilizados papéis reciclados" (TJCE, 2009b, p. 12). Evidencia-se a preocupação com a elevação de custos que poderia ser gerada com a aquisição do papel reciclado em relação ao papel branco. Os ganhos obtidos com a redução do consumo de papel por outros projetos não eram visto pelos gestores como uma folga orçamentária que permitisse a aquisição do produto recomendado pelo CNJ.

O outro ponto ainda não observado consiste em adicionar cláusulas nos contratos das licitações que selecionem fornecedores que possuam produtos ou serviços com os 
princípios básicos da sustentabilidade como, por exemplo, utilizar adequadamente os recursos naturais sem comprometer com o uso futuro. Quando indagados sobre a existência de tais mecanismos, todos os entrevistados desconheciam tal prática, mas acharam interessante a possibilidade. Uns comentaram que isso poderia ser adotado facilmente e que iam levar essa sugestão para seus chefes superiores. Desta forma, o TJCE poderá adquirir bens e materiais de consumo ambientalmente corretos, socialmente justos e economicamente viáveis, conforme a recomendação do CNJ.

\subsection{Resultados do cumprimento da Meta 6 de 2010}

O TJCE conseguiu cumprir a Meta 6 de 2010 com um percentual de 958\% (CNJ, 2011). Alcançou a redução exigida pela Meta em todos os indicadores, exceto o gasto de combustíveis. Evidenciou-se, durante as entrevistas, a preocupação inicial com o controle de custos para a promoção de práticas relacionadas com a questão socioambiental. Novamente, os aspectos financeiros servem como justificativa para a realização de projetos desta natureza. Em 2010, a chancela institucional do CNJ com o estabelecimento de metas complementou os interesses para a redução de custos. Os resultados de cada um dos indicadores da meta refletem esta perspectiva.

O TJCE continuou com os esforços para a redução do consumo de papel, principalmente com os investimentos realizados para a digitalização dos processos judiciais e administrativos. O cumprimento da Meta 6 do $\mathrm{CNJ}$ não apresentou grandes dificuldades para o TJCE, afinal a constante redução de resmas de papel impactava diretamente no cálculo. Em 2009, haviam sido consumidas 83.800 resmas, enquanto no final de 2010 a quantidade total ficou em 44.244 resmas. Portanto uma redução de 47, $20 \%$, quase a metade do consumo em apenas um único ano (CNJ, 2011).

A redução também foi significativa no consumo de água, representando 22,01\% de diminuição. Os dados de 2009 apontavam a utilização de $184.012 \mathrm{~m}^{3}$ de água. A medição final de 2010 apontou o consumo de $143.503 \mathrm{~m}^{3}$ de água (CNJ, 2011). A redução foi alcançada com a implantação de sensores nas torneiras dos banheiros, limitando a utilizando de água na lavagem de mãos e utilização dos sanitários, conforme informado pelo Secretário de Administração durante a entrevista.

Os gastos com telefone também foram reduzidos no percentual de $17,05 \%$. O gasto em 2009 ficou na ordem de $R$ \$ 5.054.266,04, enquanto em 2010 o valor final foi de $\mathrm{R} \$$ 4.192.740,2 (CNJ, 2011). A redução foi ocasionada principalmente pela maior utilização de ferramentas de comunicação online (e-mails, mensagens de texto - SMS, mensagens instantâneas - chats, etc.). A comunicação virtual foi destacada com a aquisição de novos softwares e por campanhas realizadas juntamente com os 
funcionários, conforme destacado pela Diretora de Recursos Humanos e Diretora de Tecnologia da Informação. Este indicador pode ser compreendido como exemplo de que o controle de custos é a principal justificativa para o estabelecimento desta meta com aparência de preocupação ambiental. $\mathrm{O} \mathrm{CNJ}$ não fornece nenhuma explicação que permita relacionar a diminuição do uso de telefone com o consumo de recursos naturais.

Verificou-se a redução em 15, 15\% no consumo de energia. A medição de 2009 apontava 19.024.339 kwh, enquanto o valor de 2010 ficou em 16.142.840 kwh (CNJ, 2011). O Tribunal realizou trocas de lâmpadas e de aparelhos que apontassem uma maior eficiência energética o que facilitou o alcance da meta mesmo num ano em que houve um aumento de unidades judiciais.

O único indicador em que não houve o alcance da meta foi quanto ao consumo de combustível. Houve um aumento de $19,90 \%$ no período, pois em 2009 o consumo era de 263.045 litros. Enquanto em 2010, o consumo final ficou em 315.396 litros (CNJ, 2011). O maior consumo foi ocasionado pelo aumento da frota de carros do tribunal. No ano de 2010, houve um aumento no número de desembargadores e o TJCE fornece carro com motorista para cada um dos magistrados do segundo grau. Mesmo com o aumento verificado neste quesito, a redução nos outros indicadores permitiu que o TJCE cumprisse a meta 6 de 2010.

\section{CONSIDERAÇÕES FINAIS}

Este trabalho teve por objetivo analisar os projetos e ações relacionadas à gestão ambiental implantados ou serem implantados pelo TJCE que estão de acordo com a Recomendação n.․ 11/2007 do CNJ e apresentar os resultados alcançados para o cumprimento da Meta 6 de 2010 estabelecida pelo CNJ. Esta apresenta políticas públicas que possam ser adotadas pelos Tribunais do país buscando um acompanhamento das medidas que visam à correta preservação e recuperação do meio ambiente. Buscou-se identificar os elementos necessários que permitiram adequar o Tribunal e suas comarcas ao monitoramento realizado pelo $\mathrm{CNJ}$ Ambiental.

O trabalho permitiu identificar as políticas públicas adotadas ou projetos para futura implementação no TJCE em conformidade com a recomendação do CNJ. Verificou-se que anteriormente a elaboração da referida norma, alguns projetos com princípios ambientais já eram realizados no TJCE. Os projetos de diminuição do uso de papel através da implantação do Diário da Justiça eletrônico e do Sistema PUSH de informações do andamento de processos judiciais por correio eletrônico são exemplos dessa preocupação com a preservação do meio ambiente. 
Quanto às atividades desenvolvidas ou projetos posteriores a Recomendação n.. $11 / 2007$, verificou-se que o TJCE busca atender a todos os itens recomendados, exceto a aquisição de bens e materiais de consumo que levem em consideração os princípios da sustentabilidade. Destaca-se, também, o fato de possuir 20 (vinte) comarcas monitoradas pelo CNJ Ambiental.

O projeto de maior destaque consiste na digitalização dos processos judiciais e administrativos permitindo assim uma redução significativa na utilização de papel. Vale ressaltar que o TJCE foi o primeiro Tribunal do país a enviar todos os recursos interpostos digitalizados ao Superior Tribunal de Justiça (STJ).

A ampliação da responsabilidade socioambiental consiste em um dos objetivos do Planejamento Estratégico do Poder Judiciário cearense. Portanto, esse objetivo deverá ser alcançado conjuntamente por todos os gestores, servidores e demais jurisdicionados.

Seria relevante a replicação desse estudo em outros órgãos que compõe o Poder Judiciário brasileiro. Outra sugestão consiste na realização estudo de caso comparativo entre Tribunais de uma mesma região geográfica ou de porte semelhante em termos de volume processual. Mesmo considerando que a amostra de entrevistados aqui utilizada foi adequada ao objetivo, os resultados não podem ser generalizados a cada unidade judiciária do Poder Judiciário cearense. Logo, recomenda-se que outros estudos utilizem métodos e técnicas mais aprofundadas para a coletada de dados, inclusive com a aplicação de questionários ou verificação dos indicadores ambientais.

\section{REFERÊNCIAS}

AGÊNCIA CNJ DE NOTÍCIAS. Relatório mostra um ano de gestão do ministro Gilmar Mendes à frente do CNJ. Conselho Nacional de Justiça. 2009. Disponível em: $<$ http://www.cnj.jus.br/index.php?option=com_content\&view=article\&id=7062:

relatorio-mostra-um-ano-de-gestao-do-ministro-gilmar-mendes-a-frente-do-cnj\&catid $=1$ :notas\&Itemid=675>. Acesso em: 27. Mar. 2011.

ARAGÃO, C. V. (1997). Fatores agilizadores e restritivos à atuação da Justiça do Trabalho: um estudo exploratório. Revista de Administração Pública, v. 31, n.4, p.183-215, jul/ago, 1997.

ARANTES, R. Judiciário: entre a Justiça e a Política. In: Avelar, L.; Cintra, A. O. (Org.). Sistema político brasileiro: uma introdução. 2. ed. Rio de Janeiro: Konrad-AdenauerStiftung; São Paulo: Unesp, 2007. 
BARBIERI, J. C. Políticas públicas indutoras de inovações tecnológicas ambientalmente saudáveis. Rio de Janeiro, Revista de Administração Pública. v.31, n.2, mar/abr 1997, pp.135-52.

BRASIL. Constituição da República Federativa do Brasil. Brasília: Senado, 1988.

. Lei n.. 9.795, de 27 de abril de 1999. Dispõe sobre a educação ambiental, institui a Política Nacional de Educação Ambiental e dá outras providências. (1999). Diário Oficial da União, Brasília, DF, 28 de abril de 1999. Disponível em: <http://www.planalto.gov.br/CCIVIL/Leis/L9795.htm>. Acesso em: 12. Ago. 2010.

. Decreto n.o 5.378, de 23 de fevereiro de 2005. Institui o Programa Nacional de Gestão Pública e Desburocratização - GESPÚBLICA e o Comitê Gestor do Programa Nacional de Gestão Pública e Desburocratização, e dá outras providências. (2005). Diário Oficial da União, Brasília, DF, 24 de fevereiro de 2005.

CNJ - CONSELHO NACIONAL DE JUSTIÇA. Recomendação n.ํㅜ 11, de 22 de maio de 2007. Recomenda aos Tribunais relacionados nos incisos II a VII do art. 92 da Constituição Federal de 1988, que adotem políticas públicas visando à formação e recuperação de um ambiente ecologicamente equilibrado, além da conscientização dos próprios servidores e jurisdicionados sobre a necessidade de efetiva proteção ao meio ambiente, bem como instituam comissões ambientais para o planejamento, elaboração e acompanhamento de medidas, com fixação de metas anuais, visando à correta preservação e recuperação do meio ambiente. Diário da Justiça, Brasília, DF, 28 de maio de 2007.2 Disponível em: $<$ http://www.cnj.jus.br/index.php?option=com_content\&view=article\&id=3234:recomen da-no-11\&catid=60:recomendas-do-conselho\&Itemid=515>. Acesso em: 15. Ago. 2010.

. 1ํㅡㄹ Relatório do Programa de Gestão Socioambiental do Conselho Nacional de Justiça. Disponível em:

http://www.cnj.jus.br/dpj/seer/index.php/Ambiental/article/download/38/68>. Acesso em: 19. Dez. 2010.

. Relatório final metas prioritárias do Poder Judiciário 2010. Brasília, CNJ, 2011. 
CNJ AMBIENTAL. Panorama das ações de sustentabilidade do Poder Judiciário. In: IV Fórum Governamental de Gestão Ambiental na Administração Pública, Brasília, DF, Brasil. Anais Brasília/DF: 1o de dezembro de 2009, p. 5.

DFCB - DIRETORIA DO FÓRUM CLÓVIS BEVILÁQUA. Portaria 863, de 13 de novembro de 2006. Diário da Justiça, Fortaleza, CE, 16 de novembro de 2006.

GODOY, A. S. A. A pesquisa qualitativa e sua utilização em administração de Empresas. Revista de Administração de Empresas. São Paulo: v.35, n.4, jul /ago, 1995, pp. 65-71.

GOMES, A. O.; GUIMARÃES, T. A. Desempenho no judiciário. Conceituação, estado da arte e agenda de pesquisa. Revista de Administração Pública, vol. 47, n. 2, 2013, pp. 379401.

MAIMON, D. Passaporte Verde. Rio de Janeiro, Qualitymark, 1996.

NASCIMENTO, L. F.; LEMOS, A. D. C.; MELLO, M. C. A. Gestão socioambiental estratégica. Porto Alegre: Bookman, 2008.

NOGUEIRA, J. M. M.. A ausência do Poder Judiciário enquanto objeto de estudo da Administração Pública brasileira. Revista Eletrônica Díke. v.1, n.1. jan/jul, 2011, pp. 1-17.

NOGUEIRA, J. M. M.; OLIVEIRA, K. M. M.; VASCONCELOS, A. P.; OLIVEIRA, L. G. L. Estudo exploratório da eficiência dos Tribunais de Justiça estaduais brasileiros usando a análise envoltória de dados (DEA). Revista de Administração Pública, vol. 46, n.5, 2012, pp. 1317-1340.

OLIVEIRA, L. G. L.; PONTES, D. S.; SOARES, M. N. M. A atuação da Assessoria de Planejamento do TJCE na revisão e acompanhamento do plano estratégico do Judiciário cearense. Revista Eletrônica Díke. v.1, v.1, jan/jul, 2011, pp. 18-37.

PEREIRA FILHO, H. Responsabilidade social corporativa, gestão ambiental e a norma NBR ISO 14001:2004 no contexto da Administração Judiciária brasileira. In: XI Encontro Nacional de Gestão Empresarial e Meio Ambiente, Fortaleza, CE, Brasil. Anais... Fortaleza/CE: 3 a 5 de novembro de 2009, p. 12. 
RESENDE, L. Gestão ambiental no Poder Judiciário. Monografia de Especialização. Programa de Capacitação em Poder Judiciário. FGV Direito Rio. Rio de Janeiro-RJ, 2008, p. 69.

RICHARDSON, R. J. Pesquisa social: métodos e técnicas. 3. ed. São Paulo: Atlas, 1999.

SADEK, M. T. A.; OLIVEIRA, F. L. Estudos, pesquisas e dados em Justiça. In: OLIVEIRA, F. L. (org.). Justiça em Foco: estudos empíricos. Rio de Janeiro: Editora FGV, 2012, pp. 15-62.

TJDFT - TRIBUNAL DE JUSTIÇA DO DISTRITO FEDERAL E DOS TERRITÓRIOS. Programa Viver Direito: agenda socioambiental. Disponível em: http://www.tjdft.jus.br/viverdireito/ViverDireito.pdf. Acesso em: 13. Ago. 2010.

TJCE - TRIBUNAL DE JUSTIÇA DO ESTADO DO CEARÁ. Relatório de Atividades 2007 2009. Fortaleza: Gráfica TJCE, 2009a.

. Portaria 1390, de 30 de outubro de 2009. Diário da Justiça, Fortaleza, CE, 06 de novembro de 2009. p. 12. 2009b.

. Portal Institucional. Disponível em: http://www.tjce.jus.br. Acesso em: 12. Ago. 2011. 2011a.

- TJCE fará convênio com instituições filantrópicas para doação de papéis destinados à reciclagem. Acesso em: 08. Out. 2011. 2011b.

VIEIRA; L. J. M.; PINHEIRO, I. A. Contribuições do Conselho Nacional de Justiça para a gestão do Poder Judiciário. In: XXXII Encontro da Associação Nacional de PósGraduação e Pesquisa em Administração, Rio de Janeiro, RJ, Brasil. Anais... Rio de Janeiro/RJ: 6 a 10 de setembro de 2008, p.16.

YEUNG, L. L.; AZEVEDO, P. F. Measuring efficiency of Brazilian courts with data envelopment analysis (DEA). IMA Journal of Management Mathematics, vol. 22, 2011, pp. 343-356.

YIN, R. K. Estudo de caso: planejamento e métodos. 4. ed. Porto Alegre: Bookman, 2010. 